\title{
REGLAS DE BEIJING, SU APLICACIÓN EN EL MARCO DE LAS LEYES 19.970 Y 20.084
}

\author{
The application of the Beijing Rules under Laws 19.970 and 20.084
}

Andrea Fabiola Diaz-Muñoz Bagolini*

\begin{abstract}
Resumen: Las Reglas de Beijing deben entenderse incorporadas en nuestra legislación, en el marco de lo establecido en el artículo segundo inciso segundo de la ley 20.084, que obliga a respetar los Derechos y Garantías contenidos, entre otros, en la Convención sobre los Derechos del Niño. Tal Convención establece en su preámbulo que los Estados parte recuerdan, entre otras normativas, "las Reglas Mínimas de las Naciones Unidas para la Administración de Justicia de Menores o Reglas de Beijing", lo que es un Derecho que debe ser respetado y aplicado en materia de menores. El artículo 21.2 de las Reglas prohíbe la utilización de los registros de menores delincuentes en casos subsiguientes en los que esté implicado el sujeto, ahora adulto. El Estado además debe respetar la dignidad del menor, propender a su reinserción y su intervención debe ser mínima. Por ende, no procede incorporar la huella genética de un menor en el Registro de Condenados. Jurisprudencia de la Excma. Corte Suprema es conteste en estimar que esa sanción es improcedente. De considerar los jueces de fondo que ello no es una sanción, sino un trámite administrativo, dicho Registro se deberá eliminar respecto de un menor cuando cumpla la mayoría de edad.
\end{abstract}

Palabras clave: Menores - Beijing - Derecho - Dignidad - Registro.

\begin{abstract}
The Beijing Rules must be deemed to have been incorporated into Chilean legislation due to the provisions of Article Two, Section Two of Law 20.084, which requires that the rights as well as guarantees contained, among others, in the Convention on the Rights of Child, be respected. The preamble of the Convention determines that State Parties recognize, among other regulations, "the UN Standard Minimum Rules for the Administration of Juvenile Justice or Beijing Rules", as a right that must be respected and implemented in issues involving minors. Article 21.2 of the Beijing Rules prohibits the use of criminal records in subsequent cases in which a now-adult subject is implicated. The State must also respect the dignity of minors, fostering their reintegration and propitiating minimal intervention. Thus, it is not appropriate to incorporate the DNA fingerprint of a minor in the Criminal Registry. Indeed, the Chilean Supreme Court has ruled that such a sanction is inappropriate. Furthermore, even if inclusion of minors in the Criminal Registry is not considered a criminal sanction, but rather an administrative action, records of minors should be remove upon coming-of-age.
\end{abstract}

Keywords: Children - Beijing - Law - Dignity - Criminal Registry.

\footnotetext{
*Abogada. Juez titular del $4^{\circ}$ Juzgado de Garantía de Santiago, alumna Magíster "Tutela Judicial de Derechos Fundamentales, la protección jurisdiccional en materia de género y menores", Universidad de Jaen, España. Correo electrónico: adiazmunoz@pjud.cl
}

Este artículo fue recibido el 29 de julio de 2013, siendo aprobada su publicación con fecha 2 de septiembre de 2013. 
Si las Reglas de Beijing, adoptadas por la Asamblea General de las Naciones Unidas en su resolución 40/33 de 28 de noviembre de 1985, deben ser o no aplicadas en nuestra normativa en cuanto regulan el tratamiento de menores, al amparo de la ley 20.084 y respecto de las disposiciones de la ley 19.970, ha sido un tema relevante en cuanto a la aplicación de las mismas cuando se pretende juzgar a un menor infractor de ley.

Es esencial poder determinar si dichas normas deben ser aplicadas en nuestro ordenamiento pues, en tales Reglas Mínimas de las Naciones Unidas para la Administración de Justicia de Menores, se contemplan garantías y derechos que tienden a promover el bienestar del menor en la "mayor medida posible", reduciendo el intervencionismo del Estado por las consecuencias que ello conlleva en relación con la estigmatización temprana en su calidad de persona, considerando especialmente el respeto a su dignidad y el deber del Estado en lograr su adecuada resocialización.

Dicha interrogante puede ser planteada de la siguiente manera: ¿Es posible aplicar las Reglas de Beijing en nuestro ordenamiento como "norma"? Al respecto, es esencial poder determinar una respuesta válida amparada en nuestra Constitución y demás leyes pertinentes, ya que dentro de los derechos establecidos en las Reglas de Beijing, es primordial lo dispuesto en el artículo 21.2, que establece "Los registros de menores delincuentes no se utilizarán en procesos de adultos relativos a casos subsiguientes en los que esté implicado el mismo delincuente".

Si esta norma es aplicable en nuestra legislación nacional, ¿es posible determinar si por la aplicación del mismo derecho se impide incorporar respecto de un menor la huella genética de ADN en el Registro de Condenados al tenor del artículo 17 de la Ley 19.970?

De acuerdo con nuestra jurisprudencia, la Excma. Corte Suprema ha sido reiterativa en determinar un claro criterio: la improcedencia de incorporar la huella genética de los menores infractores en el Registro de Condenados.

En efecto, el máximo tribunal, en su fallo de fecha 4 de julio de $2012^{1}$, acoge un recurso de apelación respecto de un amparo rechazado por la Iltma. Corte de Apelaciones de Concepción, dejando sin efecto la resolución adoptada por el Tribunal de Garantía de Los Ángeles, de 29 de mayo de 2012, en cuanto ordenó tomarles muestras biológicas, de conformidad a lo previsto en el artículo 17 de la Ley $\mathrm{N}^{\circ} 19.970$ respecto de los amparados C.A.F.C y N.A.M.H en los autos RUC $\mathrm{N}^{\circ}$ 1100536369-3, RIT $\mathrm{N}^{\circ}$ 2995-11 de ese mismo juzgado,

\footnotetext{
${ }^{1}$ Fallo en causa Rol 5012-2012 pronunciado por la segunda sala integrada por los Ministros Sres. Milton Juica A., Carlos Künsemüller L., Haroldo Brito C., Juan Escobar Z., contra el voto del abogado integrante Sr. Emilio Pfeffer U.
} 
considerando para ello lo dispuesto en el artículo 40.1 de la Convención sobre Derechos del Niño que dispone:

"[Q]ue los niños infractores deberán ser tratados de acuerdo con su particular dignidad, cuidando fortalecer valores y su reintegración a la sociedad, lo que encuentra reconocimiento legal en el artículo $2^{\circ}$ de la ley ya citada, en el que se dispone que en todas las actuaciones judiciales o administrativas relativas a procedimientos, sanciones y medidas aplicables a los adolescentes infractores de la ley penal, se deberá tener en consideración el interés superior del adolescente, que se expresa en el reconocimiento y respeto de sus derechos".

Agrega en su fallo, "los medios punitivos y toda la actividad estatal ante el ilícito tienen en cuenta que ha de ejecutarse sin desatender el interés superior del niño, esto es -brevemente- sin afectar el desarrollo del menor". Lo anterior es directa consecuencia de haberse aceptado que los destinatarios de unas y otras normas, los adolescentes y los adultos, son distintos, por ende, las normas "comunes", entre ellas la ley 19.970, han de entenderse como de "aplicación subsidiaria".

Y más aún, en su considerando cuarto establece que la Ley $\mathrm{N}^{\circ} 19.970$ fue dictada con anterioridad a la Ley $\mathrm{N}^{\circ} 20.084$, otra razón para determinar que no es aplicable a los adolescentes, no obstante no distinguir su texto si comprende a adultos y menores. Dicho fallo recuerda los principios de mínima intervención estatal respecto de los menores y la búsqueda de la reinserción social del adolescente, principios que no se encuentran contemplados en la Ley $\mathrm{N}^{\circ} 19.970$, más aún de acceder a la incorporación de su huella genética, los mantiene "entre infractores".

El mismo criterio ha mantenido la Excma. Corte Suprema en fallo de fecha 12 de septiembre de $2012^{2}$, donde revoca la sentencia de 31 de agosto de 2012, y en su lugar se acoge el recurso de amparo deducido por la defensa de la menor P.B.R.T y deja sin efecto la resolución adoptada por el Juzgado de Garantía de Castro, de 20 de agosto del mismo año, en cuanto ordenó dar cumplimiento a lo previsto en el artículo 17 de la Ley $\mathrm{N}^{\circ} 19.970$ respecto de la amparada, en los autos RUC No 1000778325-1, RIT No 1896-2010 de ese mismo juzgado, declarándose que ello es improcedente.

2 Fallo en causa Rol N ${ }^{\circ}$ 6931-12 dictado por la segunda sala integrada por los Ministros Sres. Milton Juica A., Hugo Dolmestch U., Juan Escobar Z. y los abogados integrantes Sres. Arnaldo Gorziglia B. y Jorge Lagos G. 
Los fundamentos se reiteran en fallo de fecha 18 de abril de $2012^{3}$, donde también revoca la sentencia de 3 de abril de 2012, escrita de fojas 35 a 37, y, en su lugar se decide acoger el recurso de amparo deducido por la defensa penal pública, en representación del menor C.R.P., en cuanto se deja sin efecto la resolución adoptada por el Tribunal Oral en lo Penal de Valparaíso, de 5 de enero del mismo año, en aquella parte que ordenó dar cumplimiento a lo previsto en el artículo 17 de la Ley $\mathrm{N}^{\circ} 19.970$ respecto del amparado, en los autos RUC $\mathrm{N}^{\circ}$ 0800960789-8, RIT No 11-2009 de ese mismo juzgado.

Además, la misma Excma. Corte con fecha 18 de julio de $2012^{4}$ revoca la sentencia de 9 de julio 2012, escrita de fojas 18 a 21, y, en su lugar se decide acoger el recurso de amparo deducido en la presentación de fojas 1 a 5 , por la defensa de responsabilidad penal adolescente, en representación del menor N.M.M. y deja sin efecto la resolución adoptada por el Décimo Tribunal de Garantía de Santiago, de 26 de junio de 2012, en cuanto ordenó dar cumplimiento a lo previsto en el artículo 17 de la Ley $\mathrm{N}^{\circ} 19.970$ respecto del amparado, en los autos RUC $\mathrm{N}^{\circ}$ 1101218233-5, RIT N 6729-11 de ese Tribunal.

En el mismo sentido se pronuncia la Excma. Corte en su fallo de fecha 19 de noviembre de $2012^{5}$, en el cual se acoge el recurso de nulidad interpuesto por la defensa penal, actuando en representación del adolescente infractor S.Y.V.C., dirigido en contra de la sentencia del Tribunal Oral en lo Penal de Quillota, de 3 de septiembre de 2012, invalidando dicha sentencia solo en la parte que ordenaba incorporar la huella genética del adolescente al Registro Nacional y dicta la sentencia de reemplazo rechazando incorporar la huella genética del menor en el referido registro por estimarlo "improcedente".

Los considerandos décimo, undécimo y duodécimo de dicho fallo, son relevantes por lo que los paso a transcribir en su integridad para un debido análisis:

DÉCIMO: Que en la especie resulta pertinente traer a colación que el Título I de la Ley $\mathrm{N}^{\circ}$ 20.084, sobre "Consecuencias de la declaración de responsabilidad de los adolescentes por infracciones a la Ley Penal", que en su párrafo $1^{\circ}$ trata "De las sanciones en

\footnotetext{
${ }^{3}$ Fallo en causa Rol N²995-12, pronunciado por la segunda sala de la Excma. Corte Suprema, integrada por los Ministros Sres. Milton Juica A., Hugo Dolmestch U., Carlos Künsemüller L., Haroldo Brito C. y Juan Escobar Z.

${ }^{4}$ Fallo en causa Rol No $5428-12$, pronunciado por la segunda sala integrada por los Ministros Sres. Milton Juica A., Hugo Dolmestch U., Carlos KünsemüllerL. y los abogados integrantes Sres. Luis Bates H. y acordada con el voto en contra del abogado integrante Sr. Guillermo Piedrabuena R., quien fue del parecer de confirmar la sentencia en alzada, por compartir sus fundamentos.

${ }^{5}$ Fallo en causa Rol No 7098-12, pronunciado por la segunda sala integrada por los Ministros Sres. Milton Juica A., Hugo Dolmestch U., Carlos Künsemüller L., Haroldo Brito C. y el abogado integrante Sr. Luis Bates H.
} 
general", disponiendo en su artículo $6^{\circ}$ que en sustitución de las penas contempladas en el Código Penal y en leyes complementarias, a las personas condenadas según esta ley solo se les aplicará la siguiente Escala General de Sanciones Penales para Adolescentes:". Posteriormente se explaya la ley sobre los diferentes tipos de castigos, en tanto que en el artículo $7^{\circ}$, referido a la sanción accesoria, se faculta al juez a establecer, en caso de ser necesario, el sometimiento a tratamiento de rehabilitación por adicción a las drogas o al alcohol.

UNDÉCIMO: Que de la reseña anterior queda de manifiesto que el referido subsistema penal no previó el registro que se discute, y toda vez que estas materias son de carácter legal, no puede menos que concluirse que cuando se decide imponerlo al recurrente se infracciona la citada Ley $\mathrm{N}^{\circ} 20.084$, por falsa aplicación, puesto que lo razonado demuestra que en la especie fue excedido el conjunto de medidas autorizadas respecto de los adolescentes infractores de ley.

DUODÉCIMO: Que así las cosas, la sentencia impugnada ha aplicado una medida que afecta claramente al adolescente sancionado como consecuencia legal e ineludible de la decisión de condena, en circunstancias que, por una parte, y como se ha demostrado, no era procedente, y, por la otra, como se evidencia de la prueba rendida, no se debatió acerca de su imposición, lo cual claramente vulnera la garantía de un justo y racional procedimiento, puesto que no se observó el contradictorio en esta parte, no obstante su carácter de mínima condición de racionalidad.

Es decir, además de la dignidad del menor, el principio de mínima intervención y la resocialización del mismo, se suma como nuevo fundamento la circunstancia de no estar incorporada la sanción accesoria de la ley 19.970 en el estatuto especial de los menores regidos por la ley 20.084 .

En el mismo sentido, con fecha 7 de noviembre de 2012, ${ }^{6}$ la Excma. Corte Suprema si bien rechaza el recurso de nulidad interpuesto por la defensa de los imputados y del menor J.B.F., actuando de oficio, precisa que la orden de recabar la huella genética en los términos del artículo 17 de la ley 19.970 es solo respecto del condenado adulto. Respecto del menor señala que dicha norma no es aplicable a los menores de edad, por cuanto no resulta ser intrascendente para un menor la inclusión para toda la vida en un registro como el creado por la Ley $\mathrm{N}^{\circ} 19.970$, agregando que la misma es muy anterior a la Ley de responsabilidad penal adolescente y por ende el legislador al crear la Ley $\mathrm{N}^{\circ} 20.084$ no tuvo en mente

\footnotetext{
${ }^{6}$ Fallo en causa Rol No 6711-2012, pronunciado por la segunda sala integrada por los Ministros Sres. Milton Juica A., Hugo Dolmestch U., Carlos Künsemüller L., Haroldo Brito C. y el abogado integrante Sr. Jorge Baraona.
} 
hacerla aplicable para los menores infractores, más aun cuando se trata de un "Registro de Condenados" por lo que la inclusión de la huella de una persona es una pena accesoria y que no aparece en el catálogo de penas de la Ley $\mathrm{N}^{\circ} 20.084$.

Ahora, sin perjuicio que la jurisprudencia de la Excma. Corte ha sido reiterativa en señalar que la aplicación del artículo 17 de la Ley $\mathrm{N}^{\circ} 19.970$, es "improcedente" en materia de menores, en los Tribunales de Garantía se ha decretado en numerosas causas, respecto de sentencias de menores infractores, la incorporación de su huella genética en el Registro de Condenados, por cuanto se estimaría que "no se trataría de una sanción, sino solo de un registro administrativo". Sin perjuicio de no compartir esa teoría y de considerar personalmente por las razones expuestas que no debe aplicarse el artículo 17 de la Ley $\mathrm{N}^{\circ} 19.970$ a los menores, resulta una realidad que se ha ordenado mediante sentencias ejecutoriadas la incorporación de la huella genética de menores.

$\mathrm{Al}$ respecto, para quienes estiman que la norma del artículo 17 de la Ley $\mathrm{N}^{\circ}$ 19.970 no constituye una sanción, sino solo el cumplimiento de un "trámite administrativo respecto de los condenados", si se accede a dicha incorporación, de contemplarse que la norma del artículo 21.2 de las Reglas de Beijing es aplicable a nuestra legislación, dicho Registro de ADN en relación con un menor condenado, debería caducar al momento en que el menor deja de ser tal y cumple los 18 años. Ello, por cuanto si el menor fuere condenado nuevamente como adulto, de no eliminar este registro, cuando cumpla la mayoría de edad, el mismo permanecerá vigente, pudiendo ser utilizado en vulneración abierta con la disposición aludida, sin perjuicio de poder interponerse en cualquier momento recurso de amparo respecto de un menor cuya huella se encuentre en el Registro de ADN.

Es necesario establecer que si bien dichas Reglas de Beijing no revisten la calidad de tratado, su normativa sí se encuentra incorporada en la Ley $\mathrm{N}^{\circ} 20.084$ en su artículo 2 inciso segundo, donde obliga a respetar los derechos y garantías contenidos entre otros, en la "Convención sobre los Derechos del Niño" aplicable a contar del 2 de septiembre de 1990.

La Convención de los Derechos del Niño establece en su preámbulo que los Estados partes "recuerdan, entre otras normativas, las Reglas minimas de las Naciones Unidas para la administración de la justicia de menores (Reglas de Beijing)". Así, en definitiva, las Reglas de Beijing forman parte de un principio rector de la Convención de los Derechos del Niño y esta a su vez debe ser respetada en todas sus garantías y derechos. Así, podríamos estimar que la normativa de las reglas de Beijing sí se encuentran amparadas en nuestra Ley $\mathrm{N}^{0} 20.084$ y deben ser aplicables en cuanto derechos y garantías a favor de los menores, siendo plausible en consecuencia determinar en el caso concreto que es un derecho de todo menor condenado como tal, si fueren nuevamente condenados ahora como adultos, que se proceda a la eliminación de los registros de sus sentencias o cualquier inclusión 
en el sistema SAF; lo que implicaría que, de acceder o de haberse accedido a la incorporación de su registro de $\mathrm{ADN}$ respecto de un menor, el mismo deberá ser eliminado cuando se cumpla la mayoría de edad por la misma razón, de lo contrario, se afectaría gravemente la dignidad de este menor, su proceso de resocialización y su libertad individual.

Al respecto, con fecha 4 de diciembre de $2012,{ }^{7}$ la Excma. Corte Suprema rechaza el recurso de nulidad interpuesto por la defensa del menor R.R.S.C., siendo destacable el voto minoritario de los Ministros Sres. Haroldo Brito C. y Juan Escobar Z., quienes fueron partidarios de acoger el recurso de nulidad fundando su voto en que es permisible hacer exigible la aplicación de las Reglas de Beijing en el ámbito judicial chileno, atendido que diversos tratados internacionales ratificados por Chile, principalmente el Pacto de San José de Costa Rica de 1991 y la Convención sobre los Derechos del Niño, establecen que el objetivo fundamental de dichos instrumentos es otorgar la debida protección de los derechos fundamentales de los niños y adolescentes en todas sus manifestaciones, en plena concordancia además con el inciso final del artículo 5 de nuestra Constitución, donde se establece el respeto de los derechos esenciales de la naturaleza humana, siendo uno de ellos el velar por el completo desarrollo de los menores de edad. Ello en estrecha relación con la obligación que impone la Resolución 40/33 de la Asamblea General de las Naciones Unidas de fecha 29 de noviembre de 1985, donde invita a los Estados parte, entre los que se encuentra nuestro país, a adoptar en su legislación, política y prácticas nacionales, las mencionadas Reglas de Beijing debiendo adoptarse las medidas necesarias para ello. Así, la regla 21.2 de Beijing impide que los registros de menores delincuentes sean utilizados en procesos de adultos relativos a casos subsiguientes donde esté implicado el mismo, debe ser imperativa, ya que si bien dichas Reglas no revisten la calidad de tratado propiamente tal, la Convención sobre los Derechos del Niño ratificada el 13 de agosto de 1990, que sí es un tratado ratificado por Chile, insta a aplicar los principios en tales Reglas.

Cabe agregar que el artículo 18 de la Ley $\mathrm{N}^{0} 19.970$ dispone que al cumplirse treinta años de ser incorporado el registro de un imputado, el Registro Civil e Identificación procederá por sí a su eliminación: Dicha norma no dispone una eliminación ipso facto respecto de los menores que hayan ingresado a dicho registro, al momento que cumplan la mayoría de edad. Por tanto, al momento de condenarse a un menor y de disponer la incorporación del registro de ADN de conformidad al artículo 17 de la Ley $\mathrm{N}^{\circ}$ 19.970, en la misma sentencia se deberá ordenar que el Registro Civil e Identificación proceda a la eliminación del mismo, cuando ese menor cumpla los 18 años de edad.

\footnotetext{
${ }^{7}$ Fallo en causa Rol N ${ }^{o}$ 7364-2012, pronunciado por la segunda sala integrada por los Ministros Sres. Haroldo Brito C., Juan Fuentes B., Juan Escobar Z., y los abogados integrantes Sres. Jorge Baraona G. y Luis Bates H.
} 
Díaz-Muñoz - Reglas de Beijing, su aplicación en el marco de las leyes 19.970 y 20.084

Finalmente cabe recordar el concepto de Derecho, que es el "orden normativo de la conducta humana que viven en sociedad inspirados en postulados de justicia", constituyendo el artículo 21.2 de las Reglas de Beijing, por ende, un "Derecho" que debe ser respetado por quienes impartimos justicia. Ese derecho se basa en la dignidad de la persona humana, en este caso, de un menor de edad, teniendo en principal consideración que la legislación aplicable siempre debe ir en beneficio del menor, considerando su resocialización y su mínima intervención. 